\title{
Geological-and-Geophysical Monitoring of Elec- trochemical Cleaning of Soil from Petroleum Pollution
}

\author{
Sergey Prostov ${ }^{1, *}$, and Evgeniy Shabanov ${ }^{1}$ \\ ${ }^{1}$ T.F. Gorbachev Kuzbass State Technical University, 650000, 28 Vesennyaya street, Kemerovo, \\ Russia
}

\begin{abstract}
The article presents the rationale and development of electro physical methods of control of the degree of soils pollution with petroleum products. The ranges of variation for the parameters of the pore space structure and wettability for the Kuzbass conditions are determined by inverse calculations on the basis of experimental data. The theoretical dependences are shown which allow us to assess the degree of soil pollution with oil products according to the results of longitudinal and areal electrical sounding. The study confirms the possibility of rapid prediction of the degree of soil contamination by measuring its electrical resistance. The database has been compiled for interpretation of the results of experimental sounding when monitoring the changes in the degree of contamination. The use of the express forecast of numerical values of the contamination factor was studied.
\end{abstract}

\section{Introduction}

One of the most dangerous soil pollutants are petroleum products: lubricants and liquid fuel $[1,2]$. The relevance of the problem of cleaning soils from oil pollution in mining industry (coal surface and underground mines, ore mines) due to large amounts of fuel consumption by road and rail transport, and lubricants in the operation of mining equipment, and technical oils in electric power plants. The refined petroleum products contain toxic watersoluble fractions [3, 4], also, gasoline, and especially motor oils contain up to $20 \%$ of additives, solvents, heavy metals. One liter of used oil may contaminate one million liters of water, not more than $60 \%$ of their volume being regenerated.

One of the effective methods for managing the soil properties, especially of low permeability (filtration coefficient $\mathrm{K}_{\mathrm{f}}<10^{-8} \mathrm{~m} / \mathrm{s}$ ), is the method of electrochemical treatment [5, 6], its main impact on the contaminated soil being the electrical destruction of ecotoxicants and the electroosmotic displacement of the diluted pollutant in the area of mechanical removal (pumping). Experimental and theoretical bases of the electrochemical method were developed for the solution of problems of technical reclamation (drainage) and for stabilizing the unstable waterlogged soils. The criteria for the rational use of this method are de-

\footnotetext{
${ }^{*}$ Corresponding author: psm.tigm@kuzstu.ru
} 
termined: the ratio of the coefficients of electroosmotic activity and filtration $\mathrm{K}_{\mathrm{e}} / \mathrm{K}_{\mathrm{f}}>10^{7}$ and electrical resistance (SER specific electrical resistivity) $\rho<8 \mathrm{Ohm} \cdot \mathrm{m}$.

Direct and indirect methods are applied to control the processes of cleaning of soils from pollution. Direct methods [7-10] (infrared spectrophotometry, ultraviolet luminescence, gas and gas-liquid chromatography) require sophisticated equipment, significant duration of the analysis and extraction of soil samples, the measurement error can reach 40$50 \%$.

\section{Materials and Methods}

Efficient monitoring of soil properties and physico-chemical processes in the area of electrobraid can be provided by geophysical methods that are effective Supplement geotechnical investigations. Very promising for the study of contaminated soils are electrical and electromagnetic methods based on the measurement of electric fields, because oil and petroleum products exhibit pronounced dielectric properties and therefore electrically contrasting. So far not very well studied and developed the following aspects of the problem of geological-geophysical monitoring of processes electrochemical cleaning of soil contaminated by petroleum products: not justified the ways of electrophysical control the degree of contamination of soils with petroleum products taking into account structural and textural parameters of the soil, its natural porosity and moisture; it is not the regularities of changes of physical and electrical properties of contaminated soils in the area of electrobraid; not developed techniques of controlled electrochemical cleaning of soil from oil pollution, to ensure rational modes of processing.

To control the degree of soil pollution with oil products, it is advisable to use the dependence of electrical resistivity of the three-phase medium on porosity, moisture and electrical resistivity of the pore filler that is used in electrical prospecting and includes structural-textural empirical parameters $[11,12]$ :

$$
\rho_{k}=\frac{\alpha \cdot K_{n}}{m^{\beta} \cdot W^{\gamma}} \cdot \rho_{\mathrm{B}}
$$

where $\mathrm{m}$ is porosity (pore cavitation); $\mathrm{W}$ - coefficient of the saturation space of the pores and cracks; $\rho_{\mathrm{B}}$ - electrical resistivity of the solution, filling pore space, Ohm·m; $K_{n}, \alpha, \beta, \gamma-$ are empirical parameters that depend on the structural and textural features of the studied soils; $K_{n}-$ is the parameter that takes into account the surface conductivity of clay microlayer on the surface of the pores; $\alpha$ - is the parameter depending on the type of geological deposits; $\beta$ is the parameter determined by the structure of the pore space (mainly by tortuosity of the channels); $\gamma$-parameter that depends on the wettability of surface pores by the solution.

The ranges of variation of the parameters of the pore space structure $\beta=1.3-2.2$ and wettability $\gamma=1.8-3.3$ should be taken for conditions of Kuzbass on the results of the inverse calculations based on experimental data; and electrical resistivity of the pore filler is calculated by the formula of harmonic weighted average for the two-component media [13]:

$$
\rho_{\mathrm{B}}{ }^{-1}=\sum_{i=1}^{n} V_{i} \cdot \rho_{i}^{-1}=V_{\ni} \cdot \rho_{\ni}^{-1}+V_{\mathrm{H}} \cdot \rho_{\mathrm{H}}^{-1},
$$

where $\rho_{\mathrm{B}}, \rho_{\mathrm{H}}, \rho_{\ni}-$ electrical resistivity of, respectively, weighted, oil and electrolyte, $\mathrm{Ohm} \cdot \mathrm{m} ; \mathrm{V}_{\mathrm{H}}, \mathrm{V}_{\ni}$ - volume fraction in the solution, respectively of the oil and electrolyte.

It was established experimentally that the change in the concentration of the aqueous solution of salt to $6.5 \%$ the value of the specific electrical resistivity decreases from 80 to 0.2 
$\mathrm{Ohm} \cdot \mathrm{m}$ and the specific electrical resistivity of engine oil and gasoline in the frequency range $\mathrm{f}=0-1 \mathrm{kHz}$ ranges $(0.2-1.1) 10^{6} \mathrm{Ohm} \cdot \mathrm{m}$. Using the experimental and theoretical dependencies obtained database specific electrical resistivity of pore filler and effective specific resistivity of a three-component medium for the specified ranges of concentrations of the aqueous solutions of the frequencies and the ratio of volume fractions of oil and electrolyte $\mathrm{V}_{\mathrm{H}} / \mathrm{V}_{\mathrm{B}}=$ $0-20$.

To automate the calculation of local contamination factor $k$ of the soil based on the experimental data of electrical soundings the algorithm, including the selection of optimal values of the structural parameters $\beta$ and $\gamma$ according to the criterion of minimum deviation of the calculated values of the effective specific resistance from the measured and calculation of $k$ values against the values of effective specific resistance in the zone of contamination and beyond.

To improve the accuracy of estimation of the degree of contamination of the proposed integral parameters of the Is and Iv, including the summation of the local values of $k$ and elemental areas or volumes for which the zone of contamination is broken with a specified step.

Algorithms that are implemented in the software package created in the software product Lazarus (environment Free Pascal).

For experimental verification of the accuracy of the calculated dependencies, and computer program the comparison of coefficients of soil contamination which were mixed in a fixed volume of waste oil at a known humidity and porosity, which showed that in the range $\mathrm{k}<$ $20 \%$ measurement error did not exceed $23 \%$.

When $\mathrm{k}>30 \%$ soil sample passed from coherent state to incoherent plastic suspension, with the consequence that the value of $\rho_{\mathrm{K}}$ and the margin of error increases dramatically. It was also found that to increase the accuracy of the calculation to adjust the value of the structural parameter $\beta$ in the prescribed nonlinear relationship with $\rho_{\mathrm{K}} / \rho_{\ni}>190$.

For the Express analysis in field studies, you can use regression based on values of $k_{3}$ from the relative values of $\rho_{\mathrm{K}} / \rho_{\mathrm{K} 0}$, with correlation coefficient $\mathrm{R}>0.9$ and have polynomial, power and linear dependence $[14,15]$.

\section{Results and Discussion}

On a one-dimensional physical model of cylindrical shape with flat electrodes in the processing in a uniform electric field confirmed that the electric contrast of the aqueous solution and the oil pollutant the use of microsensors electrical resistivity allows you to control the movement of fluids in the area of electrobraid. Found that in clean soil the natural movement of moisture occurs in the anode, causing a reduction in the level of electrical resistivity, the presence in the pores of the oil it moves in the direction of the cathode, whereby the specific electrical resistance in the measuring point increases. These processes occur relatively monotone, their intensity over time depends upon the viscosity of the contaminant (oil, fuel oil, diesel fuel, gasoline). When added to one of the electrodes of the solvent type Hexane-N is the dilution of oil, accompanied by an abrupt change in resistivity, while the processes of osmotic movement of fluids increase. In addition, it recorded a General trend to an increase in electrical resistivity associated with changes in structural and textural parameters of the soil in the electro treatment (Fig.1). 


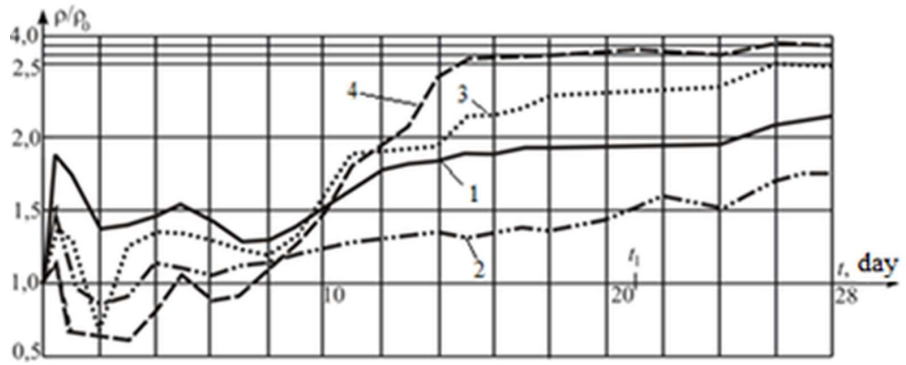

Fig. 1. Schedule changes of the relative electrical resistivity array for electrochemical purification from pollution by oil (the amount of contaminant $\mathrm{V}=100 \mathrm{~g}$ ): 1 - four-electrode sensor probe № 1;2 № 2; 3 - № 3; 4 - № 4; $\mathrm{t} 1$ - the time of the termination processing.

Studies of samples of soil showed that due to the thermal effect of electric current is the binding of moisture, coagulation of oil in the pores with increasing sizes of solid soil particles and their cohesion. The result of these processes, recorded a decrease in moisture content at all points in the model, the reduction in soil density and a sharp decrease in the content of fractions $>0.1 \mathrm{~mm}$ and the increase in the content of the larger fraction $(0,1-2,0$ $\mathrm{mm}$ ) in granulometric composition.

A closer approximation to real conditions gives a three-dimensional model at actual size fitting with two tubular electrodes-injectors, with practically applicable voltage range of $300 \mathrm{~V}$ and a current density of $15 \mathrm{~A} / \mathrm{m}^{2}$. The volume of the model was $0.15 \mathrm{~m}^{3}$. The direction of the displacement of pore-filling fluids in volume when an inhomogeneous electric field retains the aqueous solution to the anode, and the oil - to the cathode, the probability wave-like development processes, since viscosity of oil is higher than that of water. In the near-electrode regions with the greatest current density occurs anisotropy of the specific Elna interval of $\mathrm{r} \geq 90 \mathrm{~mm}$, at $\mathrm{r}=150 \mathrm{~mm}$ is smoothed, and decoracaode $I \cdot t>50 \mathrm{~A} \cdot \mathrm{h}$ due to thermal drying and consolidation of the soil, the magnitude of the resistivity increases.

Quantitative variation ranges of physical and mechanical properties of contaminated soil: the moisture content is reduced by $15-20 \%$, and a density of $2-10 \%$ in dry and wet condition (Table 1).

Table 1. The change of the physical parameters of the soil in the electro treatment.

\begin{tabular}{|c|c|c|c|}
\hline \multirow[b]{2}{*}{$\begin{array}{c}\text { Bath } \\
\text { No. location of samples }\end{array}$} & \multicolumn{3}{|c|}{ Characteristics (before/after treatment) } \\
\hline & $\begin{array}{c}\text { Wetness, } \\
\%\end{array}$ & $\begin{array}{l}\text { Density in the wet } \\
\text { condition, } \mathrm{g} / \mathrm{sm}^{3}\end{array}$ & $\begin{array}{c}\text { Density in dry } \\
\text { condition, } \mathrm{g} / \mathrm{sm}^{3}\end{array}$ \\
\hline № 1 at the +electrode & $35.3 / 28.1$ & $2.38 / 2.22$ & $1.76 / 1.728$ \\
\hline № 1 in the middle & $35.2 / 30.1$ & $2.33 / 2.2$ & $1.73 / 1.694$ \\
\hline № 1 at the - electrode & $35.2 / 29.6$ & $2.14 / 2.01$ & $1.58 / 1.55$ \\
\hline № 2 at the +electrode & $39.4 / 29.1$ & $2.51 / 2.28$ & $1.8 / 1.766$ \\
\hline № 2 in the middle & $39.4 / 31.3$ & $2.48 / 2.23$ & $1.78 / 1.746$ \\
\hline № 2 at the - electrode & $39.4 / 28.8$ & $2.44 / 2.22$ & $1.75 / 1.72$ \\
\hline
\end{tabular}

As a result of coagulation of oil on the surface of the rock particles and their adhesion is the decrease in the content of fractions $<0.1 \mathrm{~mm} 2-5$ times, and the increase in the content of fractions of $0.1 \mathrm{~mm}$ to $30-63 \%$. Particularly intensive process of change of granulometric composition of the soil occurs in the anode area (Table 2).

Table 2. Change of granulometric composition of soil in the electro treatment.

\begin{tabular}{|l|c|c|c|c|c|}
\hline \multirow{2}{*}{ Bath } & \multicolumn{5}{|c|}{ The contents of fractions (in mm) \% (before/after treatment) } \\
\cline { 2 - 6 } No. location of samples & 2 & 0.5 & 0.25 & 0.1 & $<0.1$ \\
\hline № 1 at the +electrode & $8.8 / 12$ & $33.3 / 36$ & $17.5 / 15$ & $19.2 / 19$ & $21.2 / 18$ \\
\hline № 1 in the middle & $8.8 / 9.8$ & $33.3 / 34.1$ & $17.5 / 16.2$ & $19.2 / 23$ & $21.2 / 16.9$ \\
\hline
\end{tabular}




\begin{tabular}{|l|c|c|c|c|c|}
\hline № 1 at the - electrode & $8.8 / 9.5$ & $33.3 / 37.2$ & $17.5 / 15.7$ & $19.2 / 22$ & $21.2 / 15.6$ \\
\hline № 2 at the +electrode & $8.8 / 6.1$ & $33.3 / 41.8$ & $17.5 / 15.8$ & $19.2 / 31.2$ & $21.2 / 5.1$ \\
\hline № 2 in the middle & $8.8 / 7.3$ & $33.3 / 38.2$ & $17.5 / 16.3$ & $19.2 / 26.2$ & $21.2 / 12$ \\
\hline № 2 at the - electrode & $8.8 / 8.6$ & $33.3 / 43.7$ & $17.5 / 14.5$ & $19.2 / 24.8$ & $21.2 / 8.4$ \\
\hline № 1 at the +electrode & $8.8 / 8.6$ & $33.3 / 43.7$ & $17.5 / 14.5$ & $19.2 / 24.8$ & $21.2 / 8.4$ \\
\hline
\end{tabular}

Additional introduction into the electrodes-injectors of the active substance solvent Hexane-N leads to the dilution of the oil and mixing in pores with natural moisture, which breaks the monotony of the processes of change in resistivity in the cathode region where there is additional concentration of liquid oil product, and slows down the intensity of consolidation of the soil in the anode region. especially sharply it is manifested in the soils, contaminated more viscous used oil (Fig. 2).

Conducted after completion of the processing of the extraction and visual examination of the soil confirmed the results of geological and geophysical monitoring: education of compacted soil with a characteristic dark tint in the anode region and the loose soil in natural color with spots of oil product in the cathode.

Field studies conducted at the site of OOO "NOOTSENTR", fully corresponds to the actual schemes of electrochemical treatment of polluted soils by the number of electrodes, the depth and spacing of their installation, the current regime and duration of treatment. Tested all previously applied in the laboratory types of treatment and different viscosity types of pollutants. In addition to the previously used methods of engineering-geological surveys and microsensors electrical resistivity applied integrated geophysical methodselectrical sounding with direct current, and geo-radar. The fundamental difference between the conditions of the experiment from the laboratory consisted in the fact that the experimental plot of the array are not physically isolated from the surrounding soil and atmosphere.

In General, the results of studies of samples and measurements microsensors electrical resistivity confirmed the results of laboratory experiments characterizing the patterns of change in physical properties of soils in the cathode and anode regions, but quantitatively the ranges of the properties have changed, which is associated with an additional supply of moisture from the surrounding soil and atmosphere. Thus, the range of reduction of the moisture content amounted to $3-6 \%$ and the density of 3-7 \%, the content of particles with size $<0.1 \mathrm{~mm}$ decreased depending on the type of contaminant from 1.15 to 1.61 times (Fig. 3). Visually the autopsy confirmed the formation of compacted anode zone and the concentrations of residual petroleum product.

Radar and geo-electric sounding was carried out on one longitudinal and three transverse profiles. On the GPR contaminated with petroleum products sections with a width of 2-2.4 $\mathrm{m}$ and a depth of 1.5-1.8 $\mathrm{m}$ are characterized by the weakening of horizontal lines of correlation. The graphs of electric profiling and vertical sounding data of the zone are diagnosed at higher values of effective resistivity of $\rho_{\mathrm{K}}$, the values of the integral values of $\rho_{\mathrm{K}}$ before, after contamination and after treatment were as follows: for the schema of the electro profiling, respectively with 13.1 and $21.2,17.3 \mathrm{Ohm} \cdot \mathrm{m}$; for the scheme of vertical sounding is 14.1 and $22.3,16.7 \mathrm{Ohm} \cdot \mathrm{m}$. 


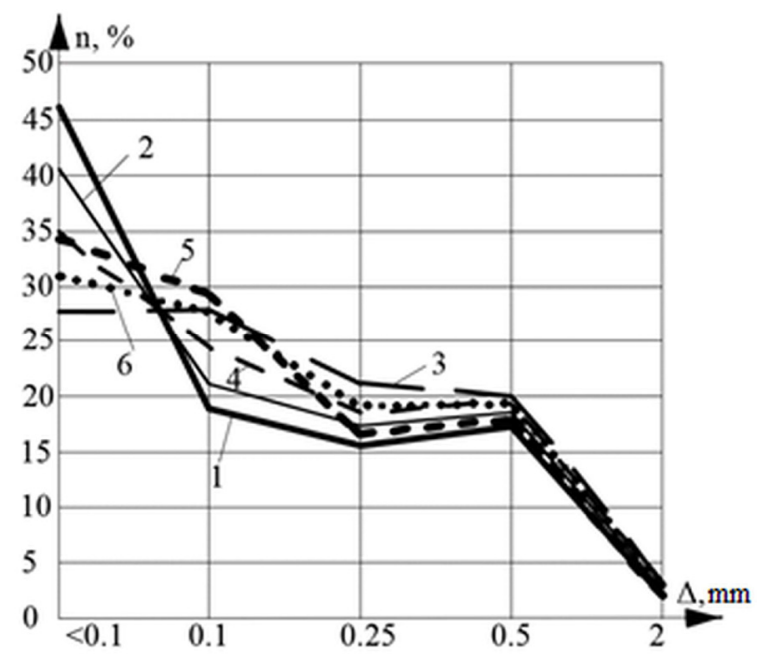

Fig. 2. The change of the granulometric composition of the soil based on type of treatment and time: 1 - clean the clay before the electro treatment; 2 - clean clay after electro-treatment; 3 - contamination by the used oil after the electro treatment; 4 - pollution gasoline after the electro treatment; 5 contamination of the used oil after the electro treatment with the solvent; 6 - pollution gasoline after the electro treatment with the solvent.

Case the detailed monitoring of changes of $\rho_{\mathrm{K}}$, when the measurement used electrodesinjectors, found that the interval time of processing $t=48-72 \mathrm{~h}$ monotonic decrease in $\rho_{\mathrm{\kappa}} 2$ 5 times with all the pollutants and the processing circuits due to migration and coagulation of the pollutant, an increase of porosity, the entry of moisture from the surrounding soil and atmosphere (Fig. 3).

By using the previously studied regression dependencies obtained that the estimated coefficient of pollution as a result of processing decreases from the known initial values of $k=$ $7 \%$ to $2-3.6 \%$ with a contamination of used oil and up to 2.6 to $4.5 \%$ - if contaminated with gasoline (Table 3).

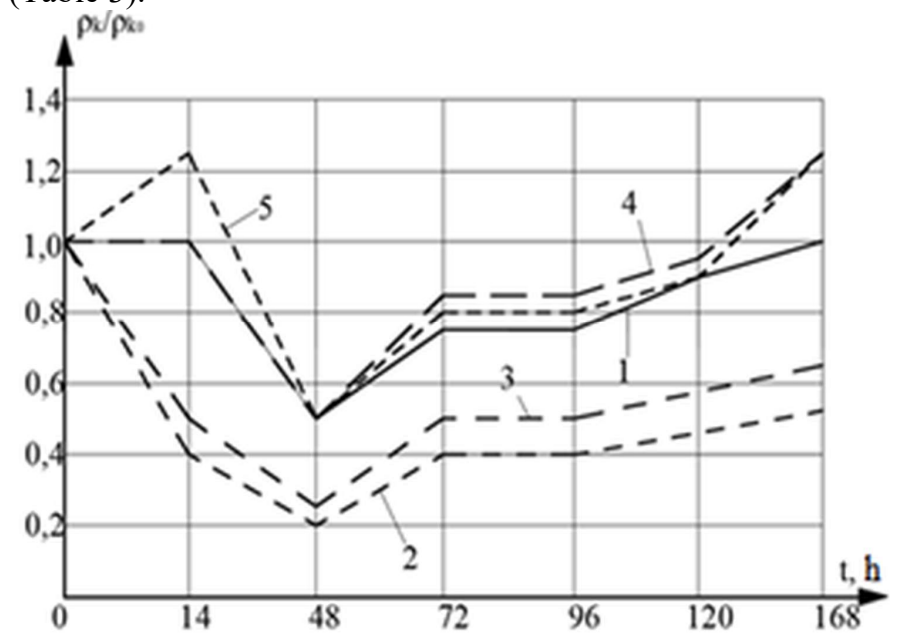

Fig. 3. Graph of changes in time $t$ of the relative effective electrical resistance $\rho_{\kappa}$ at electrical sounding in the process of experimental electrical treatment: 1 - clean clay massif; 2 - contaminated array treated with oil; 3 - array contaminated with gasoline; 4 - array contaminated with used oil and treated with solvent, 5 - array contaminated with gasoline and treated with solvent. 
Table 3. The dependence of the contamination factor $k$ from the relative change of the effective resistivity of the soil in the sample.

\begin{tabular}{|c|c|c|c|c|c|}
\hline \multirow[t]{3}{*}{ Equation } & \multirow{2}{*}{\multicolumn{2}{|c|}{$\begin{array}{c}\text { The value of the constant } \\
a \text { at pollution }\end{array}$}} & \multicolumn{3}{|c|}{ The value $k$} \\
\hline & & & \multirow[t]{2}{*}{ initial $k_{0}, \%$} & \multicolumn{2}{|c|}{ final $k_{\mathrm{K}}, \%$} \\
\hline & oil & gasoline & & oil & gasoline \\
\hline$k=a_{1} \cdot \frac{\rho_{\mathrm{K}}}{\rho_{\mathrm{K} 0}}$ & $a_{1}=2.8$ & $a_{1}=3.5$ & \multirow{4}{*}{7} & 3.64 & 4.55 \\
\hline$k=a_{2} \cdot \ln \left(\frac{\rho_{\mathrm{K}}}{\rho_{\mathrm{K} 0}}\right)$ & $a_{2}=7.64$ & $a_{2}=10.1$ & & 2.00 & 2.65 \\
\hline$k=a_{3} \cdot\left(\frac{\rho_{\mathrm{K}}}{\rho_{\mathrm{K} 0}}\right)^{2}$ & $a_{3}=1.12$ & $a_{3}=1.75$ & & 1.90 & 2.96 \\
\hline$k=a_{4} \cdot \exp \left(\frac{\rho_{\mathrm{K}}}{\rho_{\mathrm{K} 0}}\right)$ & $a_{4}=0.575$ & $a_{4}=0.95$ & & 2.11 & 3.49 \\
\hline
\end{tabular}

\section{Conclusion}

Determination of size and location (diagnosis) areas of oil contamination by the method of geo radar is provided for reducing the horizontal lines of correlation in the GPR and the method of electrical sounding positive anomalies in the graphs of vertical sounding and profiling. The result of diagnosis by the system of longitudinal and transverse profiles is a three-dimensional model of the contamination zone. Rapid control changes, contamination factor $k$ in the process of electrobraid of the soil is ensured according to the value of the effective resistivity zone under scheme of integrated sensing, using as the measuring electrodes-injectors. During the experimental trials after treatment for $168 \mathrm{~h}$ the value of $k$ when the contamination of the used oil dropped from 7 to $2.11 \%$, while pollution of gasoline up to $3.49 \%$ (exponential dependence).

Possible diagnosis of areas of contamination objects distinguish between open, partially open and closed. For each object type, for remote sensing or electrical sensing to build a model of the zone of contamination, the magnitude of the integral index $k$ take the decision on the excavation (open type) or electrochemical machining (objects partially open or closed).

Leveraging the power of the installation is ensured by increasing the voltage handling and moistening of near-electrode zones, with highlights adjustment mode or the termination of processing is determined by the stabilization of the value $k$. For an object with a volume of $200 \mathrm{~m}^{3}$, the savings in energy costs will amount to more than 14.0 thousand rubles

\section{References}

1. V. P. Seredina, Contemporary Problems of Ecology, 5, 457 (2011)

2. V. A. Efremova, Contemporary Problems of Ecology, 5, 561 (2013)

3. S. I. Kolesnikov, Russian Journal of Ecology, 3, 157 (2014)

4. T. I. Kukharchyk, Eurasian soil science, 2, 145 (2013)

5. V. A. Korolev, Journal of Environmental Science and Health. Part A: Toxic/Hazardous Substances and Environmental Engineering, 43(8), 876 (2008)

6. I. Gratchev, Soils and foundations, 3, 469 (2013)

7. C. J. Tsai, Journal of chromatographya, 1410, 60 (2015)

8. Z. Zhou, IEEE transactions on dielectrics and electrical insulation, 5, 1498 (2012) 
9. E.Y. Kovalenko, Petroleum chemistry, 2, 101 (2016)

10. S.A. Smernikov, Eurasian soil science, 10, 1059 (2008)

11. B. Leiss, Journal of structural geology, 11, 1527 (2000)

12. S. M. Prostov, V. A. Khyamyalyainen, S. P. Bakhaeva, Journal of Mining Science. 4 349 (2006)

13. G. G. Shtumpf, Journal of Mining Science, 6, 59 (1993)

14. Sergey M. Prostov, Evgeniy A. Shabanov, Proceedings of the 8th Russian-Chinese Symposium Coal in the 21st Century: Mining, Processing, Safety, 175 (2016)

15. S. M. Prostov, Proceedings of the Taishan Academic Forum - Project on Mine Disaster Prevention and Control, Atlantis Press, 433 (2014) 